\title{
El aborto y la Justicia Restaurativa
}

\author{
Isabel González Ramírez
}

Universidad Central de Chile, Santiago, Chile.

Email: igonzalezr@ucentral.cl

\section{Ma Soledad Fuentealba Martínez}

Universidad Central de Chile, Santiago, Chile.

Email: mfuentealbam@ucentral.cl

\section{Juan Pablo Llancas Hernández}

Universidad Central de Chile, Santiago, Chile.

Email: jllancash@ucentral.cl

\begin{abstract}
Resumen: El presente artículo tiene como objeto analizar el conflicto del aborto desde una perspectiva socio-jurídica con algunos aspectos psicológicos, revisando sus principales consecuencias y las posturas que han debatido a favor de despenalizar la práctica del aborto y aquellas contrarias a su falta de regulación y libre aplicación. Evaluando luego los efectos que produciría el otorgar una respuesta restaurativa a este fenómeno social, en remplazo de la aplicación de una sanción punitiva o de su simple despenalización sin otras prevenciones, medida que históricamente ha inducido a agravar o bien a invisibilizar las consecuencias propias del aborto.
\end{abstract}

Palabras clave: Aborto, planteamiento socio-jurídico, Justicia Restaurativa.

\section{Abortion and Restorative Justice}

Abstract: The starting point of this paper is the analysis of abortion from a socio-legal and psychological perspective, exploring different positions in favor and against decriminalization of this medical practice. Then, the article argues that decriminalizing the practice of abortion can aggravate or invisibilize the real consequences of this social phenomenon. Finally, the article assesses possible effects of a restorative response towards abortion in replacement of decriminalization and punishment.

Keywords: abortion, socio legal approaches of abortion, restorative justice

\section{Aborto e Justiça Restaurativa}

Resumo: Este artigo tem por objetivo analisar o conflito do aborto a partir de uma perspetiva sociojurídica com alguns aspetos psicológicos, a rever as suas principais consequências e posturas que têm sido debatidas em favor de descriminalizar a prática do aborto e aquelas contrárias à sua falta de regulamentação e livre aplicação. Seguidamente se avaliam os efeitos que produziria ao conceder uma resposta restaurativa a este fenómeno social, em substituição da aplicação de uma sanção punitiva ou de uma simples descriminalização sem outras prevenções, medida que historicamente tem levado a agravar ou tornar invisível as consequências 
próprias do aborto.

Palavras-chave: Aborto - abordagem sociojurídica- Justiça Restaurativa.

$* * *$

\section{Introducción}

El presente artículo tiene como objeto analizar el conflicto sociojurídico del aborto, fenómeno que muestra una realidad en que el Derecho como creación cultural al igual que el arte representa un reflejo de los tiempos en que se manifiesta.

Para abordar este fenómeno, no solo se reflexionara sobre el aborto consentido como un hecho social, sino que también se analizaran los fundamentos y resultados de aplicar políticas públicas tendientes a su despenalización y aquellas con tendencias divergentes, contrarias a su libre aplicación, que cuestionan que el Derecho no se haga cargo de este fenómeno y lo considere sin más una faculta que depende de una decisión individual.

En este contexto se hará referencia a las consecuencias producidas en aquellas legislaciones que lo permiten el aborto sin restricciones, en aquellas como la chilena, que prohíbe el aborto sin ninguna excepción y lo sanciona como delito, que merece una pena privativa de libertad, tanto para los terceros que lo practican para colaboran con la mujer como para ella que lo autoriza o se lo provoca y las que contemplan excepciones a su penalización, como es el caso del proyecto de ley enviado al Parlamento en Chile por el actual gobierno ${ }^{1}$, referidas al peligro para la vida de la mujer, feto aencefálico y violación de la madre, planteamiento que comparte la gran mayoría de los países que lo sancionan.

Es así como frente a la limitada oferta que plantea hoy el Derecho Penal, para abordar un conflicto tan complejo como el aborto, por medio de la aplicación de una pena y por otra parte las escazas soluciones que se proponen en los países en que este hecho se encuentra despenalizado, medida que históricamente ha inducido a invisibilizar sus consecuencias, en el presente artículo se ha considerado la posibilidad de aplicar mecanismos propios de la Justicia Restaurativa en el tratamiento de esta realidad jurídico-social, de gran ocurrencia, especialmente en países con débiles políticas públicas como los de Latinoamérica.

Ahora bien, para dar respuesta a los conflictos actuales con que se enfrenta el Derecho, como es el caso del aborto, es que se propone un sistema restaurativo, el que Marshall (1999: 17 y ss.) define como: "Un proceso a través del cual las partes que se han visto involucradas o poseen un interés en un delito en particular, resuelven de forma colectiva la manera de lidiar con las consecuencias inmediatas de este y sus repercusiones para el futuro”. Otros como Gavrielides (2012: 12), definen la Justicia Restaurativa 
como "Una moral con objetivos prácticos, para la restauración del daño, incluyendo a las partes afectadas en un encuentro directo e indirecto y un proceso de entendimiento, voluntario y con diálogo honesto”. La que incorpora una mirada de proceso y principios a su sistema.

Resultando clarificador para enmarcar los conceptos enunciados, los principios que Marshall propone (Marshall, 1999: 20 y ss.): esto es el delito como un problema compartido que necesita una solución; la aceptación de las negociaciones y el compromiso; involucrar a todas las partes afectadas; concentrarse en la reducción de los delitos futuros; valoración de la reparación por encima del castigo; búsqueda de elementos positivos en el infractor; oportunidad de rehabilitación y reconciliación; atención a las emociones y aspectos materiales del conflicto; y creatividad e innovación en la búsqueda de soluciones.

\section{Capítulo I. El aborto como un conflicto y sus consecuencias}

De modo preliminar, es posible preguntarnos si es el aborto un conflicto social o solo podemos denominarlo como un delito? Para dar respuesta a esta interrogante partiremos por enunciar algunas teorías acerca de los conflictos y sus diversas manifestaciones.

Desde un ámbito sociológico se identifican dos grandes escuelas: la primera de ellas, centrada en un área de conocimiento macro; vale decir, estudia grupos, organizaciones y sistemas sociales de gran tamaño; y la segunda, se encuentra centrada en un área de conocimiento micro, es decir, enfocada en el estudio del comportamiento humano en los contextos de interacción directa, pudiendo de este modo, diferenciarse de acuerdo al objeto de estudio. Las escuelas marxistas, el funcionalismo y el estructuralismo estarían circunscritas dentro de lo que se considera corrientes macrosociológicas, a diferencia de otras escuelas más recientes, como la etnometodología o el interaccionismo simbólico que podrían ser consideradas más cercanas a la microsociología (Cadarso, 2014).

Otra forma de identificar las escuelas consiste en catalogarlas entre teorías del consenso o del conflicto, siendo importante destacar que dicha denominación se circunscribe sobre el enfoque macrosociológico. Es así, como en el marco de las teorías del consenso, por una parte destacan las escuelas funcionalista y el estructuralista, las que a través de una mirada de comunidad buscan alcanzar el orden de la estructura social, entre otros objetivos. Por otro lado, las teorías del conflicto consignan la imposibilidad de evadir el surgimiento de éste en las relaciones humanas; consideran el cambio social, siendo las más destacadas la escuela marxista y la de Frankfurt (Cadarso, 2014).

Posteriormente, teóricos como Humberto Maturana, analiza el fenómeno del conflicto desde el lenguaje y la interacción entre los seres humanos, obviando el estudio centrado en comunidades (Maturana,1991). Sólo entonces, se comienza a estudiar como los seres humanos en contextos 
sociales, construyen cognitivamente el mundo en el que viven.

Para Maturana, no existiría caos o conflicto en un estado natural en las relaciones humanas, debido a que la armonía del vivir se construye en la convivencia, en la aceptación del otro. (Maturana, H. 1991). La vida humana ocurre en conversaciones, conjugándose cruces comunicacionales, desde una lógica no lineal.

En la misma línea, Florencia Brandoni (Arechaga, P.; Brandoni, F.; y Risolía, M., 2005: 39) considera que "el conflicto es inherente a la condición del sujeto humano, en tanto seres de lenguaje, para quienes hablar es producir equívocos, cadenas significantes que implican malentendido”. Por su parte, a juicio de Remo Entelman (2002), no existiría otra alternativa más que convivir con los conflictos, dada la imposibilidad de evitarlos.

La idea de una sociedad sin conflictos sólo es pensable para un mundo de individuos que conviven en un espacio sin escasez y que carecen de imaginación para pretender alcanzar nuevos objetivos en abundancia” (Entelman, 2002). Escasez que encontramos presente en las causas de hechos que afectan bienes jurídicos como el aborto.

Basándose en la imposibilidad de erradicar el conflicto y regresando la atención al individuo, Josep Redorta (2004) aporta a la definición de conflicto, dada por Rubin, Pruitt y Hee afirmando que "el conflicto significa diferencia de intereses percibida, o una creencia que las partes, en sus aspiraciones normales, no pueden alcanzar simultáneamente” (Redorta, J., 2004). En la misma línea, para Leonardo Schvarstein, los conflictos se construyen por los seres humanos, ya que "una situación es vivida como conflicto si es significada como tal” y una misma situación puede ser conflictiva para unos sujetos y no para otros (Arechaga, P.; Brandoni, F.; y Risolía, M., 2005: 75).

Ahora bien el aborto sin duda desde esta perspectiva es un conflicto, ya que contrapone posiciones, valores y objetivos entre sus partícipes y la comunidad, siendo imposible que sea percibido por las personas de la misma manera en un mismo momento y lugar, entendiendo que tiene múltiples causas, consecuencias y reacciones.

Siendo así, el aborto puede concebirse como un conflicto, entre la sociedad, que conlleva su determinación de sancionarlo o despenalizarlo y la mujer que aborta enfrentada a sus consecuencias sociales, jurídicas y psicológicas, estrechamente vinculadas entre sí, que son causas y efectos unas de otros recíprocamente y también manifestaciones de la realidad de su época, como ocurre en países con fuerte represión política y social, donde se castigaba el aborto para proteger el aumenta de la natalidad.

Sin embargo el aborto, como manifestación de un conflicto así concebido, no puede ser ignorado, ya que se origina principalmente en las desigualdades sociales, provocadas por la pobreza y el desamparo, que 
emanan de la falta de educación sexual y la pérdida de recursos de control social informal, como son las redes de contención familiares, de la comunidad cercana, amigos, vecinos y compañeros de trabajo entre otros, las que generalmente se interrumpen como dice Bustos, (Bustos, J.,2005: 25-27), por la emigración de las familias de lo rural a la ciudad, lo que hace surgir como forma de represión el control social formal que proviene del Derecho Penal.

Derecho que aplica sanciones a acciones como el aborto, denominando delitos, a los que son más bien conflictos penales, que afectan bienes jurídicos valorables para la comunidad, como la vida y salud, que son de responsabilidad social más que individual.

También Zaffaroni (2003: 36), abordan el delito desde paradigmas menos retributivos observándolo como un conflicto. Sosteniendo que es casi un equívoco lingüístico el que lleva a que se hable de "el" delito, cuando es de toda evidencia que éste no existe, pues ónticamente sólo existen conflictos arbitrariamente seleccionados, conjunto muy heterogéneo de hipótesis conflictivas que, con buena voluntad pueden llamarse "delitos".

Luego en el sistema penal, por definición estructural falta el titular del bien afectado, como en el aborto, pero el poder del sistema penal no puede evitar cobrar la culpa, sin poner en crisis su propio ejercicio de poder. Modelo punitivo que no resuelve los conflictos, sino que "se limita a imponer una pena, sin considerar las necesidades de la víctima”. El conflicto queda colgado hasta que se disuelve, no se resuelve (Zaffaroni, 2003: 37).

Tampoco hay realmente un culpable en el aborto, debido a que existe una estrecha relación entre la incidencia de sus prácticas y las deficientes condiciones económicas, sociales y culturales que ofrecen las distintas regiones a sus ciudadanos. Así, se aprecia que los países con alta incidencia de abortos, se caracterizan por ser aquellos más pobres y donde su relación con la mortalidad de las mujeres es significativa (Bermúdez, 1998: 51).

Una de las consecuencias sociales vinculadas a las psico-jurídicas que produce el aborto, son las que operan en ciudades conservadoras, o con fuertes tintes ideológicos, esto es la discriminación social, que produce la sanción moral y el desarraigo social, que sufren las mujeres que se practican un aborto, las que sin perjuicio del dolor por su perdida y la sensación de culpa, padecen una exclusión social, enfrentadas a una pena (CASAs L.; 1996).

La consecuencia jurídica de la pena, afecta especialmente a las mujeres de medios socio-económicos más vulnerables, ya que a diferencia de lo que ocurre en los grupos más privilegiados, el aborto se hace público, producto de las enfermedades contraídas por los precarios medios empleados, su falta de higiene y escasos conocimientos médicos de quienes lo practican, terminando con la muerte de la mujer, su esterilidad y en ocasio- 
nes con una sanción por la que pierden su trabajo, la custodia de sus hijos y aprecio del medio.

Por otra parte, la Conferencia Mundial sobre Población y Desarrollo, El Cairo (1994), y la Conferencia Mundial sobre la Mujer, Beijing (1995), han puesto especial énfasis en la relación entre derechos humanos y derechos sexuales y re- productivos, entendidos éstos como el derecho de hombres y mujeres a decidir libremente y tener opciones en lo concerniente a la libertad y seguridad de la persona, sexualidad, derecho a la vida, reproducción, calidad de atención en salud, acceso a la información y privacidad y con?dencialidad en la toma de decisiones referidas a la salud sexual y reproductiva, derechos que el Estado tiene la responsabilidad de no transgredir y adoptar las medidas que sean necesarias para asegurar su ejercicio (Dides, 2006).

Es así como, el reconocimiento de estos derechos ha llevado a que la legislaciones de muchos países despenalicen el aborto, sin embargo la causa no parece ser solo un logro en cuanto a los derechos reproductivos de las mujeres, afirma Rabinovich-Berkman (2014: 89) ya que el aborto aparece como el resultado de intentos promovido por una política Estatal, que a modo de conveniencia de algunos grupos, o como solución para los sectores de menos recursos, intenta evitar que las personas que no se consideran un aporte a la sociedad se reproduzcan, reduciendo los costos económicos que para el fisco significaría un parto y la posterior subvención en los ámbitos sociales a ciudadano de menores recursos.

Otro de los objetivos que subyacen como ideologías bajo la despenalización del aborto, sostiene este autor, es el crear una sociedad genéticamente homogénea. Así el Estado desde una mirada eugenésica, realiza una selección de quienes son óptimos para integrar la sociedad, excluyendo a quienes vienen con una carga genética dudosa, ya sea porque son embarazos de padres drogadictos, o con conductas desviadas, productos de una violación, o por que provienen de familias que no pueden darle un desarrollo adecuado.

Situación que encuentra similar justificación a la prohibición que existía antaño para acceder al matrimonio y tener descendencia, cuando existían precedentes de patologías mentales, las que se basaban en postulados de Darwin en relación a la selección natural de las especies y búsqueda de una supremacía racial, la que justificaba genocidios (Ibid: 70).

Vinculada a las consecuencias sociales de optar por despenalizar o no el aborto, están las propias del ámbito jurídico, donde encontramos la experiencia comparada de países en que está despenalizado el aborto, con aquellos que lo sancionan y la situación de los que aceptan el aborto terapéutico, frecuentemente bajo tres condiciones: peligro para la vida de la mujer, feto aencefálico y violación de la madre, como se propone en el proyecto chileno. 
$\mathrm{Al}$ respecto se puede observar que cada Estado establece su normativa en base a elementos propios de su cultura, demografía, desarrollo e ideología política. Así por ejemplo, la realidad europea y norteamericana dista mucho de lo que acontece en países africanos y en los sudamericanos, donde las posibilidades de abortar amparadas por la legislación nacional son nulas o muy restrictivas, viviéndose en éstos países hoy, un importante debate en cuanto a las posibilidades de incorporar en su normativa un derecho más amplio a la mujer para decidir sobre su propio cuerpo y la interrupción del embarazo.

En países sudamericanos como Paraguay y Brasil, el aborto sólo puede ser considerado cuando peligre la salud de la mujer, lo que en Chile se permite en la práctica, pero no bajo una autorización normativa expresa, ya que el Código Penal no contempla la hipótesis del aborto terapéutico, como lo hacía antes en el código sanitario, pero por medio de la analogía legal, se ha podido considerar estado de necesidad exculpante, al colisionar derechos fundamentales ${ }^{2}$. Restricción que en Europa sólo acontece en Andorra e Irlanda.

Siguiendo el panorama americano, en Argentina el aborto es permitido bajo ciertas hipótesis, del artículo $86^{\circ}$ del Código Penal que sanciona a médicos, cirujanos, parteras o farmacéuticos que abusaren de su ciencia o arte causando aborto o cooperaren a efectuarlo, salvo que sea causado para proteger la salud de la madre o en los embarazos provenientes de una violación o de un atentado al pudor cometido sobre una mujer demente.

Otro país americano que permite el aborto bajo ciertas condiciones es México, su Código Penal, modificado el 2009, establece que el aborto no será punible en los casos expresados en el artículo $251^{\circ}$ : el aborto realizado como resultado de una acción culposa de la mujer embarazada; cuando el embarazo sea resultado de un delito de violación; en casos de que corra peligro de muerte la mujer embarazada; y cuando a juicio de dos médicos exista prueba suficiente para diagnosticar que el feto sufre alteraciones genéticas que pueda nacer con trastornos físicos o mentales graves, aceptando la madre.

Comentario aparte merece Estados Unidos, donde a raíz del caso Rode vs. Wade ${ }^{3}$ y de Doe vs. Bolton ${ }^{4}$, en 1973 se declaró ilegal la prohibición del aborto por la Suprema Corte norteamericana, acogiendo la idea de que viola la 14 enmienda de la Constitución. Revirtiéndose decisiones judiciales en torno a la penalización del aborto y convirtiéndose en un referente a nivel mundial, al determinar que todas las leyes federales y estatales de EEUU debían ser modificadas, en cuanto proscribían o restringían el aborto, bajo el amparo del derecho a la privacidad, enmarcado en el debido proceso de la $14^{\circ}$ enmienda ${ }^{5}$.

Otra excepción en la región se encuentra en Uruguay, donde la interrupción del embarazo a solicitud de la mujer no es punible, con la ley $\mathrm{N}^{\circ}$ 19.987, sobre Interrupción voluntaria del embarazo, el año 2012, en su artí- 
culo $3^{\circ}$ relativo a los requisitos para la práctica del aborto, señala que el equipo médico informará sobre las alternativas al aborto provocado, con los programas disponibles de apoyo social y económico, así como la posibilidad de la adopción del hijo. Con una buena práctica, en la que un equipo interdisciplinario le otorgue apoyo psicológico, social e información a la mujer, para contribuir a superar las causas que la induzcan al aborto.

En cambio, en el panorama europeo, existe un consenso mayor sobre la despenalización del aborto, así por ejemplo, España dicto la ley 2/2010 de salud sexual y reproductiva y de la interrupción voluntaria del embarazo, adecuando su normativa al consenso de la comunidad internacional, mediante la actualización de sus políticas públicas y la incorporación de servicios de atención de la salud sexual y reproductiva. Frente a la convicción, de que una buena educación afectiva sexual y reproductiva, el acceso universal a prácticas clínicas efectivas de planificación de la reproducción, mediante anticonceptivos de última generación, en sistema público y programas de salud sexual y reproductiva, es un medio de prevenir infecciones de transmisión sexual, embarazos no deseados y abortos.

Experiencia que parece ser buena práctica de protección de la vida prenatal a través de políticas activas de apoyo a las mujeres embarazadas y a la maternidad. Así tutelando el bien jurídico al inicio de la gestación, su protección se articula a través de la voluntad de la mujer, y no contra ella. Permitiéndole adoptar su decisión en un plazo razonable, tras haber sido informada clara y objetivamente de todas las prestaciones y derechos a los que puede acceder durante el embarazo, sus consecuencias y las de la interrupción del mismo.

En el Reino Unido el aborto es legal debido a la existencia de la Abortion Act de 1967, autorizado bajo los supuestos de evitar lesiones graves permanentes a la integridad física o salud mental de la mujer; hasta las 24 semanas de gestación; y supuestos en que el embrión o feto puede ser afectado por discapacidad física o mental. Acta con la incorporación 1990 de la HFE Act, Ley sobre Fertilización Humana y Embriología.

En países europeos desarrollados como Suiza, Bélgica, Rumania, Suecia, Italia, Francia y Austria aplica iguales plazos y condiciones citadas para permite el aborto.

En el continente asiático, el aborto es permitido en China, donde debido a su contexto político y demográfico se considera imprescindible por el gobierno de China para la estabilidad de la población y alcanzar la política de hijo único evitando la superpoblación.

Otros países asiáticos donde se permite el aborto con condiciones son: Rusia, Kazajistán, Vietnam. Con mayor exigencias se encuentran Tailandia, India, Japón y Corea. 
África por su parte, mantiene una política restrictiva respecto al aborto, con la excepción de Sudáfrica, donde existe la ley del año 1997 de "Libre Elección respecto a la Interrupción del Embarazo", que permite el aborto sin ninguna restricción durante las primeras doce semanas de gestación. Esto ha logrado, según Organización para la salud de las mujeres, reducir en un $91 \%$ la mortalidad materna y en $50 \%$ las lesiones ${ }^{6}$.

Por otra parte justificando la opción jurídica del no penalizar el aborto encontramos sus consecuencias psicológicas y emocionales, que se encuentran especialmente en el caso de la población adolescente, donde desde la psicología del comportamiento encuentra algunos aspectos de duelo y perjuicio emocional experimentado por las mujeres tras adoptar esta opción, pero no tan directamente relacionados con su accionar.

Una de las primeras investigaciones en torno a las consecuencias psiquiátricas de la interrupción voluntaria del embarazo, se vislumbra con Lask (1975: 41), primer investigador en elaborar una escala para predecir el riesgo psicológico del aborto, concluyendo que aquellas manifestaciones psíquicas pesquisadas en la muestra, obedecían mayormente al entorno al que pertenecían, más que a la situación de aborto propiamente.

De esta manera, se encontró una escasa incidencia de sintomatología psiquiátrica vinculada con la interrupción voluntaria del embarazo. No obstante se concluyó que existen una serie de indicadores predictores de consecuencias psicológicas tras un aborto, tales como: ser multípara; haber sido abandonada por la pareja; ser inmigrante; tener entre 21 y 30 años; presentar antecedentes de trastornos psiquiátricos; y las actitudes de su entorno.

Así como la de Lask, existen una serie de investigaciones experimentales que confirmar la escasa incidencia de consecuencias psiquiátricas en mujeres que han optado por abortar. Tal es el caso de Belssey (1977: 71), que a partir de un seguimiento de 360 mujeres inglesas, en los primeros tres meses de embarazo y tres meses posterior a la realización del aborto legal, concluye que sólo un escaso porcentaje presentó algún trastorno emocional, y que se debía más probablemente a factores pre- existentes en las mujeres, tales como historia psicosocial inestable, vínculos familiares empobrecidos, deficiencia de procesos de socialización y desadaptación laboral.

Por otro lado, existen otras investigaciones que demuestran una mayor incidencia de depresión, en mujeres en situación de post parto, que en aquellas que se encuentran en periodo post aborto. Así también, se aprecian mayores consecuencias emocionales en mujeres a las que se les ha denegado el aborto y se las ha forzado a una maternidad (Ibid).

Conforme a lo anterior, es posible reforzar la hipótesis de que el aborto no presentaría mayores consecuencias emocionales de las que representa el parto para una mujer. Situación que se atenuaría aún más, cuan- 
do se realiza tempranamente el procedimiento de aborto, que cuando se da de manera espontánea, situación que tiene consecuencias psicológicas más traumatizantes, al no contar con preparación y apoyo psicológico.

No obstante lo anterior, también existe referencia en algunas investigaciones, al duelo experimentado por aquellas mujeres que optan por realizarse un aborto, que se homologan a aquella sintomatología de carácter emocional experimentada tras un duelo causado por muerte de un sujeto cercano a la persona (Lask, 1975: 173), situación frente a la cual resulta indispensable el acompañamiento de un profesional de la salud mental, lo que precisamente se propone en los estudios referentes a la despenalización del aborto, de manera de contar con un sistema de acompañamiento previo y posterior a la decisión adoptada. Los antecedentes expuestos con anterioridad, nos permiten observar como las consecuencias sociales, jurídicas y psicológicas del aborto, están íntimamente unidas y son causas y efectos entre sí, lo que se observa en la opción jurídica de penalizar o no el aborto.

\section{Capítulo II. Argumentos a favor de la despenalización del aborto y contrarios a no regularlo legalmente}

Las regulaciones jurídicas no se pueden escapar a los patrones culturales, es así como siempre han existido diversas razones para justificar la penalización del aborto. En el siglo V a. c. en Atenas, dentro de las escasas prohibiciones que contempla el juramento Hipocrático, está la de darle a una mujer una bebida que le permitiera abortar, por lo que parece importante para la sociedad de esa época evitar el aborto, no por tratarse de un tema de Derechos Humanos, sino que en razón de que la concepción humana eran hijos para utilidad de la polis. En Roma al producto de la concepción humana se le llamaba eso que está en el útero, referido como una cosa (RabinovichBerkman, 2014: 64)

Los códigos penales en un comienzo permitían el aborto por enfermedad o peligro de la vida de la madre, violación o inviabilidad del feto, excepciones que nacen en períodos que se aprueba la eugenesia, que pretendía proteger a la comunidad de hijos enfermos, procurando su procedencia del matrimonio, asegurando así riqueza genética y su crianza en un espacio protegido, Rabinovich-Berkman (2014: 66-69).

La cuestión sobre si la mujer tiene o no derecho a interrumpir el embarazo, por tener autonomía y libertad para decidirlo, es un tema actual, que vino con la defensa de los derechos de la mujer, en la segunda mitad del siglo XX, donde se plantean posturas de despenalización del aborto basadas en el derecho a la autonomía de la mujer y a los derechos sobre su propio cuerpo, donde solo ella debe decidir sobre su concepción.

Sin embargo, señala Claudia Dides (2002), el debate sobre el tema de la despenalización del aborto se ha enfocado solamente en aspectos técnicos y biomédicos, eludiéndose la discusión sobre el contenido y alcance de los derechos involucrados, que requieren un cambio de paradigma, donde 
la construcción de los derechos sexuales y reproductivos, debe entenderse como derechos y libertades fundamentales de todas las personas, sin discriminación, que permiten adoptar libremente, una amplia gama de decisiones sobre aspectos consustanciales a la vida humana"

Para efectos de evaluar esta realidad socio jurídica, se expondrán a continuación argumentos a favor de despenalizar el aborto y en contra de permitirlo sin restricción.

Argumentos a favor de despenalizar el aborto: Históricamente el aborto ha sido una práctica común a lo largo del desarrollo de la especie humana, conociéndose antecedentes del fenómeno en la cultura griega y romana, donde filósofos como Aristóteles, justificaba esta práctica en cuanto se realizara "antes que el embrión reciba sentimiento y tenga vida, posterior a ello, sería un crimen” (Martínez, 1940: 247).

Asimismo, en la Iglesia Católica, se aceptó hasta el año 1869 (Encíclica Apostolicae Sedis) la teoría de la animación retardada, conforme a la cual el alma entraba al cuerpo a los cuarenta días contados desde la concepción en el hombre y a los ochenta en la mujer.

Si bien en la actualidad, se han desarrollado teorías acordes a los adelantos de la ciencia, existe diversidad de opinión en cuanto al comienzo de la vida y la posibilidad de determinar si la práctica del aborto es o no punible. De esta manera, la teoría de la anidación del óvulo fecundado en la matriz del útero, permite afirmar el momento en el que dicho óvulo fecundado es merecedor de protección penal. Sin embargo, existen otras teorías que establecen el inicio de la vida humana en un momento posterior (Ossandón, 2012: 347).

La primera de ellas es la que establece el inicio de la vida sólo a partir de los 14 días posteriores a la fecundación; otra afirma que hay vida cuando existen las primeras manifestaciones del sistema nervioso central, las que se aprecian a los 48 días posteriores a la fecundación; una tercera establece que un elemento característico de la vida humana es tener intereses propios, lo que sólo puede producirse al tener una vida independiente de la madre, es decir, al estar en presencia de un sujeto viable, situación que ocurre a partir del tercer trimestre de gestación. La última hipótesis plantea que la característica de la vida humana la constituye el hecho de ser reconocida por los demás, circunstancia que ni un feto ni un recién nacido poseen (Henríquez, 2000: 130).

Desde este argumento de las teorías biológicas sobre el inicio de la vida humana se ha abordado el tema del aborto, refutando que ésta se inicie con la fecundación del óvulo, para justificar la despenalización de esta práctica, en cuanto no afectaría la vida.

Por otra parte, otro de los argumentos a favor de despenalizar el aborto dice relación con los efectos psicológicos, a los que se ha hecho 
referencia, los que no demuestran que el aborto cause peores efectos psicológicos que las depresiones post parto, los abortos espontáneos o los partos en condiciones forzadas para la mujer y que las circunstancias psicológicas negativas más bien se refieren al temor por las consecuencias del entorno.

Otros argumentos que se destaca en la posición a favor de aceptar el aborto como una práctica válida y despenalizarlo, se traduce en la defensa de los derechos de la mujer y su capacidad de decidir sobre su propio cuerpo, que al inicio fue solo bandera del feminismo.

Al respecto cabe señalar que desde la clásica consigna feminista de “el cuerpo es mío”, se comprende la negación del sometimiento del cuerpo femenino a decisiones heterónomas o que se justifican en intereses ajenos a la propia mujer, no siendo facultad del Estado, la imposición de la gestación y maternidad en las mujeres.

En este sentido plantea Ferrajoli (1990: 85) “la lesión del segundo imperativo kantiano, según el cual ninguna persona puede ser tratada como medio o instrumento - aunque sea de procreación - para fines no propios, sino sólo como fin en sí misma”, así la regulación jurídica del aborto debería dar cuenta de la situación de las mujeres conforme a su capacidad generativa, combinando el legítimo interés de protección a la vida con el respeto a la autonomía femenina y su salud (García, C. 2007).

Por ello, en la actualidad se desarrollan en los Estados mecanismo a través de los cuales se otorga reconocimiento a la autonomía de los sujetos, lo que significa reafirmar su libre elección de establecer planes personales en pos del desarrollo de valores anhelados, elección que no debería ser interferida por la facultad del Estado, estableciendo sistemas de persecución que nieguen la autodeterminación de las mujeres en materias de procreación.

Pero para hacer efectivo el ejercicio de estos derechos, además de ser necesario acceder a la respectiva información, servicios y medios que permitan la adecuada toma de decisiones (Dides, 2002), debe reconocerse el derecho a tener la posibilidad de acceder al máximo de placer, bienestar y felicidad (Dides, C; Casas, L., 2007). Por ello, es que se considera como un gran logro, la implementación de la anticoncepción de emergencia y esterilización voluntaria, sin embargo, la discusión pendiente en Chile sobre el aborto y su despenalización, lleva a reflexionar sobre derechos de profesionales de salud y usuarios enfrentados y ausentes en la resolución de sus conflictos (Dides, C; Casas, L., 2007: 205).

Un denominador común de esta permanente discusión es la tensión que se produce entre la valoración socio-histórica y políticamente condicionada de la maternidad, y el carácter subjetivo de un proceso que ocurre -en concreto- en el espacio íntimo-sexual y, en el cuerpo humano femenino. Dicha tensión, según Claudia Dides (2006), es un aspecto que trasciende a las prácticas de salud, porque devela de qué manera la reproducción 
humana y sus consecuencias a pesar de constituir asuntos del ámbito privado y vida afectiva de las personas, se transforman temas políticos cuando requiere crear políticas públicas.

Las diferencias ideológicas, señala (Dides, 2007: 224-225), se basan en valoraciones distintas que política, social y culturalmente se asignan no sólo a la maternidad, sino al ejercicio de la sexualidad y reproducción, hecho de la intimidad personal y no público.

Limitar este derecho podría llevar a una negación del carácter de sujetos autónomos al género femenino, al interferir en la capacidad de elección de la significativa decisión sobre la maternidad. Produciéndose así un significativo estancamiento en el progreso de los derechos de las mujeres, denominados de primera generación, e identificados como derechos de autonomía o libertad, a la maternidad (García, C. 2007: 205).

También es importante considerar que en gran medida la sanción social frente a esta práctica recae principalmente en aspectos de índole religioso o de ciertos credos que cuestionan la facultad del ser humano de decidir sobre la vida de otro. Lo que parece incongruente ante la realidad, de que no toda muerte de un ser humano es penalizada, (Bermúdez, 1998: 156), como es el caso de la guerra que promueve eliminar al enemigo.

Finalmente, una razón argumentada a favor de legalizar el aborto, es que reduciría el riesgo para la vida y la salud de las mujeres permitiendo el control de las condiciones en que estas prácticas abortivas se ejecutan, limitándose además la comercialización de prácticas abortivas clandestinas de numerosas clínicas.

En la actualidad existen cifras sobre 46 millones de abortos a nivel mundial, de los que 16 millones se practican de manera ilegal ${ }^{7}$. Siendo América Latina el lugar donde se practican 3.700 .000 abortos inseguros al año, en que mueren 68.000 , con riesgo del $13 \%$ de mujeres. Un ejemplo de esto es Argentina, donde un $40 \%$ de las camas de hospitales públicos se encuentran utilizadas por pacientes que presentan complicaciones por abortos (Bermúdez, 1998: 129 y ss.). Al igual que en Brasil, donde un número significativo de mujeres pobres y de sectores rurales se someten a desastrosas prácticas abortivas.

Son todas las razones antes expuestas, las que se usan entre otras para argumentar que el Estado debiese garantizar a la mujer la libertad individual a la reproducción humana, respetando el derecho a interrumpir su embarazo, ya sea por condiciones de salud, edad, económicas o sociales desfavorables para el adecuado cuidado de un hijo. Para lo que se aduce que la decisión individual de abortar debiese basarse en el reconocimiento y validación por parte del Estado, de la autonomía personal de la mujer.

También la normativa legal apoya la despenalización del aborto: Los derechos del que está por nacer, en la mayoría de las legislaciones se en- 
cuentran protegidos por la Constitución y preservados en instituciones como el derecho de herencia y filiación, entre otros, normativa que como ocurre en Chile le reconoce sus derechos futuros, sin embargo, no le concede los atributos propios de la personalidad, sino hasta el parto.

Lo que se ratifica según Ossandón en el art. $1^{\circ}$ de nuestra Constitución, que establece que las personas nacen libres e iguales en dignidad y derechos, lo que significa que la personalidad se adquiere con el nacimiento. Por otra parte, el artículo $19 \mathrm{~N}^{\mathrm{o}} 1$ de la Constitución hace un tratamiento diferenciado respecto del nasciturus, asegurando en el inciso $1^{\circ}$ a todas las personas el derecho a la vida; mientras que el segundo establece que la ley protege la vida del que está por nacer. Si el nasciturus fuese persona y se le reconociera constitucionalmente un derecho a la vida, no tiene sentido destinarle un inciso especial; en el ordenamiento jurídico, persona es el ser humano nacido (Ossandón, 2012: 348).

Así mismo el Código Civil chileno en su artículo 74º, dispone: La existencia legal de toda persona principia al nacer, esto es, al separarse completamente de la madre. En consecuencia, solo con el nacimiento comienza la existencia legal de la persona (Ibid).

Tampoco el Código Penal chileno, parece considerar el aborto un atentado contra la vida, no ubicado este delito en el título donde se encuentran los delitos contra la vida, título VIII, sino en el título VII, donde están los delitos contra el orden de la familia, la moralidad pública y la integridad sexual, lo que se explica por razones históricas ya aludidas (Garrido, 2010: 98), sobre que antes el aborto se veía como una afección a la comunidad y familia. Lo que sin duda no se aplicable en la actualidad, porque generalmente el aborto se da en mujeres solas y en privado, por lo que tampoco afectaría la moralidad pública.

Así también, nuestro Código Penal concibe una menor pena por la muerte del más indefenso, en el caso de la madre y sus ascendientes, que dan muerte a un niño de menos de 48 horas contadas desde el parto, figura privilegiada respecto del parricidio, que merece menor pena que matar a un infante, lo que se justificaba por razones de cultura de la época, que protegía la honra de la mujer, al igual que algunas sanciones atenuadas en el aborto.

Desde los argumentos en contra de aceptar el aborto como una práctica libre y sin regulación legal, Parecen contradictorios los planteamientos legislativos que atenúan la protección del que está por nacer y sancionan con severidad los atentados contra la vida, ya que estamos frente al mismo ser que en unos meses será un niño/a, sujeto de derecho y centro principal de protección de los derechos humanos, por ser más indefenso que otros. (Rodríguez, 2001).

Afirman los contrarios al aborto, negarle naturaleza humana al feto y protección jurídica, por el solo hecho de no haber sido expulsado del vien- 
tre materno, lugar donde la naturaleza lo ubica los primeros meses de vida por requerir mayor cuidado y dársela fuera cuando es similar su indefensión (Barzelatto J, Calderon MC; 1996. 12.)

Es así como, los argumentos que ponen en duda aceptar el aborto como un derecho propio de la mujer, dicen relación con la existencia de una coalición de derechos fundamentales, (considerados así para quienes aceptan que el aborto afecta el derecho a la vida, y solo de coalición de principios jurídicos para otros que no lo aceptan), entre la vida del que está por nacer, y los derechos de la mujer y su autonomía para decidir sobre sí.

Se ha mostrado como la cultura separa ficticiamente por etapas cronológicas la vida de un ser humano, en su tránsito de embrión a feto, infante, adolescente, adulto y anciano, sin considerar que estamos frente a la misma persona. Donde si bien el feto no tiene todo el desarrollo de un niño, tampoco el niño lo tiene respecto del adolescente, ni éste del adulto, pero nadie pensaría por eso desconocer los derechos del niño o adolecente, o plantear que uno tiene más derechos a la vida que otro, sino al contrario, entre menor desarrollo y más indefenso más se protegen sus derechos, (niños y ancianos) (Soto; Román; Rojas, 2009).

Es así como algunos afirman que se repite la discriminación y desigualdad que se produce en todos los ámbitos de nuestra sociedad, respecto a priorizar el respeto y defensa de los más poderosos, invisibilizando los derechos de los más débiles, los que no tienen voz, al carecer de poder para defender sus derechos, y en este caso además no parece políticamente correcto priorizar sus derechos, por sobre los de libertad y autonomía de la mujer, los que hoy son socialmente más aceptados y progresistas. (Foro de Salud y Derechos Sexuales y Reproductivos y Red de Salud de las Mujeres L. y del Caribe; 2005).

Para algunos, no existe duda que ambos derechos merecen el mismo respeto y que el Estado deben poner a disposición todos sus medios para protegerlos. Pero también es cierto que debieran aplicarse similares criterios a los usados en otras situaciones complejas de coalición de derechos fundamentales o principios, en que se permite sacrificar un bien jurídico para salvaguardar otro, como en el caso del estado de necesidad, donde siempre debe optarse por preservar el bien jurídico de mayor valor (Jakobs, 1997, 419).

Argumentando en esta línea se podría llegar a afirmar que si se trata de proteger derechos de la madre a optar libremente sobre su maternidad, también debiera protegerse el derecho del padre a su paternidad, y en esta línea podría éste exigir el nacimiento de esa criatura o decidir sobre no ser padre, y aún contra la voluntad de la madre exigir el aborto de ese ser que está por nacer, aludiendo a su derecho a optar por la paternidad o no y la carga de obligaciones que esta conlleva. 
Adicionalmente, podría afirmarse, que nuestra legislación consagra criterios de oportunidad a las personas, para disponer de sus derechos, como la institución de la prescripción, entonces porque no debiéramos aplicar estos al aborto. Esto significa que la mujer sin duda tiene derecho a decidir sobre su propio cuerpo y sobre su maternidad, pero tiene una oportunidad de ejercer su derecho antes de afectarlo voluntariamente, antes del embarazo, cuando aún no se ha creado otra vida.

Lo anterior, en el caso de ser voluntario el origen del embarazo, ya que en casos de violación, no se da este presupuesto, sino que deben apreciarse otros factores, tales como ¿si el mal provocado a la madre, debe conllevar como otra consecuencias de afectación el nacimiento de un hijo no deseado? ¿y si evitar este gravamen a una a niña o mujer abusada, es prioritario sobre el derecho a la vida del que está por nacer?

En esta misma línea, podría sostenerse que es cierto que un embarazo no deseado puede afectar la salud de la madre, su derecho a desarrollarse y a la libertad de orientar su vida, imponiéndole el embarazo cargas económicas y psicológicas no previstas y no queridas, lo que daría según algunos derecho a la mujer a terminar con esa gestación, pero entonces el mismo derecho tendría la madre a terminar con la vida de su hijo cuando ya fuera del vientre materno, éste enferma gravemente, afectándole otros derechos similares.

Así parece que este complejo problema se trata con criterios cronológicos propios de nuestra cultura, situándose en los extremos de la vida su gestación y vejez, la mayor de las desprotecciones que da el Derecho a las personas.

\section{Capítulo III. La aplicación de mecanismos restaurativos al aborto}

Si el aborto debe considerarse o no delito no es la principal cuestión, sino de que se trata de un conflicto social relevante, que requiere respuestas e instrumentos que ofrezcan mejores alternativas que la pena, ya que como dice Bergalli, ¿Cómo se puede aceptar la pretensión de un sistema jurídico, de responder con los mismos instrumentos y los mismos procedimientos, a conflictos de tan vasta heterogeneidad? (Bergalli, 2003: 34). Para lo que podemos pensar en ocupar otros instrumentos para su tratamiento como los que ofrece la Justicia Restaurativa, que cambia el paradigma del sistema represivo ocupado hasta ahora.

En este sentido Baratta (1987: 107-119) dice que el sistema penal no es apto para proporcionar las defensas más eficaces de los derechos de las personas, por el hecho de que su intervención está estructuralmente limitada a la formulación de respuestas sintomáticas a los delitos, cuando éstos ya se han manifestado dentro del sistema social.

Desde la perspectiva de la aplicación del Derecho Penal, mediante un procedimiento que debe necesariamente ser selectivo, se dejan conflic- 
tos criminales sin resolver y los resueltos no siempre lo son de una forma satisfactoria para los ciudadanos, especialmente por la falta de participación colaborativa de las partes en su proceso de resolución.

Además, como dice García-Pablos de Molina (1988: 604-640) la criminalidad es fomentada por el control social formal y el sistema penal, los que producen el etiquetamiento del delincuente. Sugiriendo que la aplicación de una pena ni previene ni corrige, todo lo contrario, corrompe y estimula futuros actos desviados estigmatizando al infractor, por lo que deben buscarse alternativas a la pena que restauren a las partes.

En el caso concreto del aborto voluntario, es complejo hablar de delito, ya que siendo así debiéramos consignar la responsabilidad en la mujer, lo que no es tan exacto considerando que la mujer que aborta es víctima de una realidad social, frente a la cual no ha podido actuar de otra manera. Siendo así, este conflicto requiere ser abordado por medio de la restauración y contención a la mujer víctima de una situación social no querida.

La Justicia Restaurativa, se ha propuesto como una oferta complementaria a la pena y también como sustitutiva a ésta, donde solo es oportuno esperar la intervención del Estado en la medida en que no quepa obtener de los directamente interesados una resolución equitativa al conflicto (Eiser, 1999: 122. Siendo así puede proponérsele como método para dar una solución integral al aborto, entendido como una acción que afecta a bienes jurídicos que la sociedad quiere proteger, para lo que se necesita incorporar soluciones que amplíen la mirada retributiva de la pena, que solo contribuye a fomentar el daño y rencor causado.

Es así como si se adopta la estructura de la disciplina propia de la Justicia Restaurativa, llamada Ventana de la disciplina social, Mc Cold (2000), donde frente a una infracción deben aplicarse dos elementos fundamentales, un alto control y un alto apoyo para mantener la disciplina social y desmitificar la concepción del castigo. Lo que requiere de límites bien definidos y exigencia en el cumplimiento de las normas y en el caso del control, la asistencia permanente e interés centrado en el bienestar y apoyo del infractor. Permitiéndose que se confronte y desapruebe la infracción, pero logrando al mismo tiempo, el reconocimiento de los valores del infractor. Mirada reintegradora que resignifica el hecho y compromete al infractor, propiciando una participación colaborativa y reflexiva de los involucrados para establecer procesos de sanación y aceptación de responsabilidad.

Conforme a lo señalado, es que existe un vínculo con el segundo aspecto de la Justicia Restaurativa, la relación entre el daño causado por la infracción y la necesidad de los afectados, partes interesadas que son de manera primarias y secundarias, según si su afectación emocional es directa o indirecta. Los que en un procedimiento restaurativo podrían convertirse en comunidades de apoyo, además de manifestar sus propias necesidades facilitando la subsanación y restauración del daño ocasionado. 
La forma de participación de los interesados dependerá de la tipología de prácticas restaurativas usada, las que son formales e informales. Las informales permiten manifestaciones emocionales y toma de conciencia a partir de la comunicación entre partes.

Entre las emociones que se identifican en víctima y ofensor, destaca la vergüenza, regulador crítico del comportamiento social humano Nathanson (2011). Para sentirla, no es imprescindible la realización de una acción calificada como negativa, ya que bastaría que el sujeto experimentara que existe “algo” Tomkins (2011), que interrumpe el interés-emoción o el gozo-jubilo, (Nathanson, 2011), lo que explica que la sienta también la víctima. Frente a la que se puede reaccionar con un “ataque a los demás”, lo que sería el responsable de la expansión de la violencia en la vida moderna. Permitiendo las prácticas restaurativas una oportunidad para que se exprese la vergüenza y con esto reducir su intensidad.

Por otro lado, las prácticas formales involucran a más personas, requiriendo para ello, mayor tiempo de planificación, así como una estructura más formal y completa. Ambos tipos de prácticas, promueven la expresión de afectos, condición indispensable para la formación del tejido social y por ende, el establecimiento del sentido de comunidad.

Entre los beneficios de un sistema retributivo se ha podido corroborar que permite al desjudicializar, destinar recursos focalizadamente, ofrece mayores oportunidades para iniciar un proceso educativo y socializante, donde el infractor en este caso los participes del aborto, asumen más responsabilidades y se enfrenta a lo dañino de su acción.

La víctima por su parte, representada por la familia y comunidad es acogida en su dimensión personal y humana, permitiendo a las partes desarrollar habilidades en la resolución del conflicto de manera no violenta, disminuyendo la probabilidad de reincidencia y aportando a prevenir nuevas situaciones como estas.

En cuanto a la reparación a la víctima, entendiendo que esta puede ser económica, social y/o moral y que en el caso del aborto, debiera tratarse de una reparación más bien social y moral, con aspectos materiales y simbólicos, proporcional al daño causado a la comunidad, dentro de la cual también se debe contemplar a la mujer que se ha provocado un aborto como víctima parte de la comunidad afectada y a su vez como ofensora.

Como autora del hecho ha sufrido un grave quiebre con la comunidad, en el sentido que ha realizado un hecho que gran parte de la comunidad no aprueba en el aspecto moral y por lo que la discriminan del resto de su género, sintiéndose rechazada. Pero también ella percibe que esa sociedad no le ha ofrecido a ella las oportunidades y acogida que ella necesitaba, lo que causo se encontrara en la situación de abortar. Es este quiebre de dolor, arrepentimiento, rencor y vergüenza el que requiere ser reparado mediante medidas de mitigación reales y oportuna, que se ofrecen mutua- 
mente la sociedad a la mujer, que son mutuamente víctimas y ofensores, tales como reconocimiento de su falta de oportunidades de su dolor, inclusión laboral y terapia y ésta a la sociedad, participando en terapia, orientación sexual, ofreciendo su testimonio y aporte o trabajo comunitario.

La Justicia Restaurativa, probada en experiencias comparadas, permite concluir que este es un modelo que incluye mecanismos colaborativos que aportan soluciones más integrales y satisfactorias a la comunidad (Galaway, 1985: 626), y a las partes, otorgándoles la posibilidad de asumir su responsabilidad personal en los hechos, lo que facilitará su posterior reinserción social, y disminuirá las posibilidades de reincidencia.

Lo anterior permite un modelo democrático que deviene en una acción social participativa y racional, ventaja que constituyen la justificación que ha tenido este trabajo para tratar de la aplicación de la Justicia Restaurativa al aborto, sistema validado por las recomendaciones de los organismos internacionales (Villán Duran, 2002: 153 y ss.) como: Naciones Unidas, Consejo de Europa, Unión Europea, Consejo Económico y Social ${ }^{8}$.

Los óptimos resultados de la aplicación de este sistema restaurativo, han ayudado a promover sus mecanismos, especialmente el de la mediación penal y otros de mayor participación comunitaria, los más conocidos son: La Conferencia del Grupo Familiar, en adelante CGF, que consiste en que frente a una infracción especialmente juvenil y existiendo o no una acusación formal, se desarrolla un proceso de diálogo, con el objetivo de discutir la conducta de el o los jóvenes involucrados y los hechos acontecidos antes y durante el delito, proponiendo un plan para el futuro. Este procedimiento usa una metodología definida por un funcionario designado del Departamento de Trabajo Social, quien convoca; al infractor, su familia, la víctima, un trabajador social, un representante de la División de Apoyo de Jóvenes de la Policía y a otros representantes de la comunidad. CGF, en Canadá tienen lugar respecto de una amplia gama de delitos (Parson, 2006: 112).

A diferencia del CGF, en las Conferencias Comunitarias, el encuentro del victimario es con una víctima sustituta, no la real y en la reparación no participa la familia del acusado sino la comunidad (Jaccoud, 2006: 106).

En cambio los Tratados de paz o círculos de sentencia: tiene por objeto hacer partícipes a miembros de la comunidad, víctimas, defensores, agresores, policía, fiscales y jueces entre otros, de un plan de sentencia apropiada y que recoja todos los intereses de los participantes sentido y valores de la comunidad, en orden a reparar o curar a los afectados, promoviendo la participación de todos los presentes, para crear soluciones constructivas. (Blanco, Díaz, Heskia y Rojas, 2004: 82 y ss.).

También encontramos el encuentro entre víctima y agresor, el círculo de sanación y los paneles de víctimas y victimarios, en países como Australia, Nueva Zelanda Canadá Reino Unido, EEUU ${ }^{9}$. Pero uno de los más inte- 
resantes es la Pizarra restaurativa (Mera, 2009: 165-195), mecanismo basado en el reconocimiento público del error por el infractor, tratado éste con cuidado y protección por la comunidad y con dureza la infracción.

Los mecanismos mencionados corresponden a perfiles más comunitarios que el de la Mediación víctima-infractor, entendiendo por ella: “Un proceso voluntario de solución de conflictos penales el que permite a la víctima reunirse cara a cara con el agresor, guiado por un tercero imparcial, que en forma colaborativa busca el restablecimiento del equilibrio roto por la transgresión ocasionada por un delito u ofensa, mediante la restauración de sus consecuencias y la reconciliación de los afectados con la sociedad," ${ }^{10}$. Uno de los primeros programas de mediación vinculados a la justicia restaurativa fue el Victim-Offender Reconciliation Programme, VORP, en EEUU que tuvo como objetivo principal otorgar las condiciones para que la reconciliación sea posible entre las partes y el de Victim-Offender Mediation Programmes, VOM, (Umbrett, Mark: 1994).

Desde este marco de desarrollo internacional, es que la opción de incorporar los sistemas restaurativos como forma de solución del aborto, parece oportuna.

Ahora considerando que uno de los mecanismos más utilizados en nuestra realidad latinoamericana, es el de la mediación penal, es válido analizar si sirve como posible tratamiento del aborto. Uso que por una parte parece acertado, ya que ésta propicia un aumento de responsabilidad de los afectados en el conflicto y en su proceso de resolución, por medio del dialogo, sin embargo como en el caso de un aborto no existen siempre identificado claramente una víctima y un ofensor, ya que en esta situaciones todos los son, especialmente la madre y comunidad, parece más apropiado utilizar otros mecanismos restaurativos que incluyan mayormente a la comunidad, como la pizarra restaurativa, la conferencia familiar o comunitaria, el circulo de sentencias, entre otros. Dejando la mediación para situaciones en que el aborto involucre intereses contrapuestos que sea necesario tratar en forma directa entre la mujer y el padre o familia de la criatura.

Ahora bien, el aborto como hemos expuesto puede entenderse como un conflicto, ya sea entre la mujer y su pareja o esta y su familia o comunidad, La intervención y apropiación del Estado de los conflictos, se realiza mediante diferentes políticas con fines preventivos, disuasivos y reactivos (Binder, 2011: 170-171). Todos ellos se reflejan en la opción de someter a la mujer y sus colaboradores al proceso judicial, lo que no parece apropiado si consideramos que las causas seguirán existiendo, más allá del problema concreto que es objeto del juicio. Lo que no significa que el Estado deba desentenderse de este grave conflicto, al contrario, debe coordinar las acciones sociales para prevenirlo antes que se produzca y acoger sus consecuencias una vez producido.

Es razonable entonces sostener, que cuando consideramos el aborto un delito, es visto éste como una violación al Estado, adquiriendo el con- 
flicto un carácter interpersonal entre el Estado y el agresor, sustituyéndose el daño que se ocasionó a la vida con el perjuicio producido al Estado, que reacciona sancionando.

Sin embargo esta penalización de la acción abortiva voluntaria de la mujer, no previene su comisión, ni evita su reincidencia, es más produce una alta cifra negra sobre este delito, que no se denuncia y que como lo demuestran innumerables estudios, provoca dañinas consecuencias debido a su clandestinidad, sobre la vida y salud de mujeres, especialmente las de más escasos recursos, que deben realizar esta intervención en lugares indignos, con falta de higiene y carencia de conocimientos médicos.

Tampoco la libre determinación sobre el aborto sin ninguna regulación jurídica o responsabilización del Estado sobre este fenómeno es razonable, ya que como se ha señalado invisibiliza sus nefastas consecuencias, Siendo necesario asumir este conflicto.

Desde esta perspectiva, parece útil aplicar para el tratamiento del aborto, alguno de los mecanismos de la Justicia Restaurativa, que requieren mayor participación comunitaria, que citamos, dejando la mediación para situaciones particulares, con partes individualizadas y en que alguien se siente personalmente afectado como lo casos mencionados.

\section{Conclusiones}

El aunar criterios para obtener una visión uniforme sobre la aceptación o rechazo de la despenalización del aborto o sobre su libertad de determinación, sin regulación normativa, no es hoy ni será nunca una cuestión tan fácil de resolver, es entonces prudente detenerse a reflexionar sobre las condiciones y factores previos a la decisión que una mujer pueda adoptar sobre la interrupción anticipada de su embarazo. Desde lo que resulta fundamental, más allá de las regulaciones legislativas, profundizar sobre la necesidad de políticas públicas que permitan tomar decisiones antes del aborto, en base a condiciones mínimas de las mujeres tendientes al respeto de ciertas garantías fundamentales.

Esto, dado a que la práctica del aborto, se debe principalmente a la imposibilidad de contar con políticas públicas sexuales y reproductiva claras, que contemplen procesos educativos en relación a la formación afectiva y sexual de las mujeres.

Conforme a ello, es que en países de mayor desarrollo, donde se ha despenalización el aborto, se han adoptado medidas de educación temprana en esta materia, creación de redes de cuidado significativas para las mujeres. Es así como es posible apreciar que a nivel internacional, existen países donde además de legislar favorablemente sobre el aborto, han debido desarrollar políticas públicas que permiten evitar las situaciones en las que una decisión de tal naturaleza deba adoptarse, a partir de la facilitación 
de recursos de prevención, información y otorgamiento de condiciones que eviten el aborto o le ofrezcan buenas condiciones sanitarias básicas.

Ahora bien, sin perjuicio de no considerar ninguna de los autores de este artículo, positivo el hecho del aborto y realmente una infortunio para la sociedad, la mujer y los derechos del que está por nacer, tampoco parece posible encontrar en la punición una solución para este fenómeno, ya que suma a este desafortunado hecho, producto de la pobreza y el desamparo, intervenciones clandestinas que afectan la salud y vida de la mujer, por la ausencia de higiene y de profesionales médicos, debiendo asumir además ésta en el evento de quedar vivas, una pena que las desarraiga de su medio social.

Sin embargo, uno de los riesgos de la despenalización es que se invisibiliza el fenómeno del aborto. Siendo así, no puede usarse esta política como excusa del Estado y la comunidad para limitar la procreación de los sectores más vulnerables ni para ignorar sus consecuencias, dejando a la mujer abandonada a su suerte.

Ahora bien, aunque el Estado ofrezca a la mujer que aborta, los medios para otorgarle apoyo médico, esto terminará siendo un gravamen más de aquellos que nuestras sociedades con grandes niveles de desigualdad imponen a las personas de menos recursos, que son las que al adolecer de una educación fortalecida en el plano sexual y carecen de condiciones para prevenir un embarazo no deseado o de enfrentar el nacimiento de un hijo, siendo éstas las permanentes víctimas de este flagelo.

Una opción a estas alternativas que puede proponerse para abordar el aborto voluntario de la mujer y de sus colaboradores, es tratar el conflicto integralmente mediante un proceso restaurativo, con mecanismos adecuados a cada cultura nacional.

Adelantando propuestas, por las características propias del aborto, y la necesidad de incorporar a la comunidad al tratamiento de este fenómeno, el mecanismo que parece más adecuado es la Conferencia del Grupo Familiar, que consiste en que frente a una infracción o delito, se desarrolla un proceso de diálogo, con el objetivo de discutir la conducta de los actores y los hechos acontecidos antes y durante la infracción o delito, proponiendo un plan para el futuro. Este procedimiento usa una metodología definida por un funcionario público, quien convoca; al infractor, su familia, la víctima, un trabajador social, un representante del Ministerio de Salud, de la Policía y otros representantes de la comunidad.

En esta línea, es la comunidad la que debe responsabilizarse, mediante la aplicación de mecanismos restaurativos, que permitan a la mujer y a la sociedad restablecer el quiebre producido, reinsertando socialmente a la mujer, la que necesita ser reparada y acogida por su comunidad cercana debido a sus carencias y a su vez reparar a la comunidad, la que tampoco deseaba que se afectara la vida humana de ninguna manera. 
Así las cosas, en el caso de encontrarse penalizado por la ley penal el aborto, debiera considerarse como alternativa al juicio y a la pena el proceso restaurativo, el que sin lugar a dudas será un mejor aporte para la sociedad que una pena privativa de libertad, donde podrían usarse algunos mecanismos restaurativos como los que hemos mencionado, donde participa la comunidad apoyando a los directa e indirectamente involucrados, de manera de tratar en comunidad el conflicto, acoger y contener a la mujer, revisar las circunstancias en que ocurrieron los hechos, ayudando a la mujer a procesar y entender las razones que la condujeron a tomar esa decisión y proponer posibilidades de reparación para los afectados.

Reparación que debe colaborar a que estos hechos no vuelvan a ocurrir, comprometiéndose la mujer y los terceros que participaron en el aborto, a trabajar en proyectos comunitarios, en colegios, municipios y lugares que agrupen a jóvenes, aportando para la prevención del embarazo no deseado, entregando su testimonio, con educación sexual y afectiva, acogiendo y apoyando a las mujeres que se encuentren frente a situación de decidir sobre el aborto o una vez ocurrido, mitigar sus consecuencias

Ahora, si no está legalmente penado el aborto en una jurisdicción, se podría igualmente ocupar mecanismos restaurativos para tratar este conflicto, mediante formas de mediación comunitaria, debido a que parecería equivoco ocupar frente a este hecho no delictual un mecanismo de mediación penal.

Sin embargo como los conflictos comunitarios son la antesala de los de naturaleza penal, que generalmente dan pie a una posterior y obligatoria intervención del Derecho Penal, como el aborto con consecuencias de muere de la madre, parece indispensable usar esta forma colaborativa de prevenir y resolver este conflicto de una forma más humana como es la propuesta restaurativa. 


\section{Notas}

${ }^{1}$ Boletín: El último proyecto legislativo tendiente a despenalizar el aborto los constituye el boletín $N^{\circ}$ 9895-11 de fecha 31 de Enero de 2015, el cual regula la despenalización de la interrupción voluntaria del embarazo en tres causales. Esta propuesta legislativa autoriza la práctica del aborto en casos de violación, inviabilidad fetal y riesgo vital de la madre. http://www.camara.cl/pley/pley_detalle.aspx? prmID=10315\&prmBL=9895-11

${ }^{2}$ Explicación sobre si es coalición de derechos fundamentales o principios jurídicos, más adelante.

${ }^{3}$ El contenido central de Roe v. Wade es que el aborto debe ser permitido a la mujer, por cualquier razón, hasta el momento en que el feto se transforme en "viable", es decir, sea potencialmente capaz de vivir fuera del útero materno, sin ayuda artificial. La viabilidad se coloca cerca de los siete meses (28 semanas) pero puede ocurrir antes, incluso en las 24 semanas. Antes de esta "línea de la viabilidad", la Corte sostuvo que el aborto debe estar disponible cuando sea necesario para proteger la salud de la mujer. Véase sentencia en http://caselaw.lp.findlaw.com/scripts/getcase.pl?court=us\&vol= 410\&invol=113, última visita 28 de Marzo de 2014.

${ }^{4}$ La sentencia del caso Doe contra Bolton, del 22 de enero de 1973, estableció que el aborto inducido debe ser legal cuando sea necesario para proteger la salud de la mujer. Disponible en http://www.law.cornell.edu/supremecourt/text/410/179, última visita 28 de Marzo de 2014.

${ }^{5}$ Referente al otorgamiento por parte del Estado, a protección igualitaria a todas las personas ante la ley.

${ }^{6}$ Se recomienda consultar el mapa de Reproductive Rights, para observar la realidad del aborto en el mundo. Mapa completo disponible en http://www.worldabortionlaws.com/ map/ El Centro de Derechos Reproductivos es una organización de defensa legal sin fines de lucro dedicada a la promoción y defensa de los derechos reproductivos de las mujeres en todo el mundo. Última visita el 28 de Marzo de 2014.

${ }^{7}$ http://www.womenslinkworldwide.org/pdf_programs/es_prog_rr_col_factsheets_ cifras.pdf (última visita el 02 de abril de 2014)

${ }^{8}$ El artículo 10 de la mencionada Decisión Marco prescribe "Los Estados miembros procurarán impulsar la mediación en las causas penales para las infracciones que a su juicio se presten a este tipo de medidas (....) Velarán para que pueda tomarse en consideración todo acuerdo entre víctima e inculpado que se haya alcanzado con ocasión de la mediación. Decisión Marco del Consejo de la Unión Europea de 15 de marzo de 2001, (2001/220/JAI), Diario Oficial nº L 082 de 22 de marzo de 2001, p. 0001-0004.

${ }^{9}$ Information and Resource Center, www.vorp.com en Asheville, Carolina del Norte, www.restorativejustice.info, última visita: junio 2011.

${ }^{10}$ Acta de conclusiones de la mesa de la mesa temática de Mediación Penal, Red Nacional de Acceso a la Justicia, Ministerio de Justicia, Santiago, http:// www.accesoalajusticia.cl [Última visita Agosto 2012]. 


\section{Bibliografía}

Arechaga, Patricia, Brandoni, Florencia y Risolia, Matilde (comps) (2005), La Trama de Papel. Sobre el proceso de mediación, los conflictos y la mediación penal. Editorial Galerna, Buenos Aires.

Baratta, Alessandro (1987), “Notas para una teoría de la liberación”, en Revista Poder y Control, Editorial PPU. N 1, Barcelona.

Barzelatto J, Calderon MC, Isaacs S, et al., "El aborto en Chile. Elementos para el debate”. CORSAPS, Santiago de Chile; 1996. 12. Beck U, Giddens A, Lash S. Modernización reflexiva.

Belsey E.M.; Greer H.S.; Lal S.; Lewis S.C.; Beard R.W. (1977), "Predictive Factors in Emotional Response to Abortion: King's Termination Study IV”, en Social Science and Medicine, vol. 11, N², 1977, pp. 71-82, UK.

Bergalli, Roberto (2003), Sistema penal y problema social, Ed. Tirant lo Blanch, Valencia.

Bermúdez Valdivia, Violeta (1998), La regulación jurídica del aborto en América Latina y El caribe. Editorial Cladem (Comité de América Latina y El Caribe para la defensa de los derechos de la mujer), Perú.

Binder, Alberto (2011), Análisis Político Criminal, Editorial Astrea.

Blanco, Rafael; Diaz, Alejandra; Heskia, Joanna y Rojas, Hugo (2004), "Justicia Restaurativa: Marco Teórico, Experiencias Comparadas y Propuestas de Política Pública”, artículo de la Colección de Investigaciones Jurídicas Universidad Alberto Hurtado, $\mathrm{N}^{\circ}$ 6, Santiago, Chile.

Braithwaite, John (1989), Crime, Shame and Reintegration, Cambridge University Press, Cambridge.

Dides, Claudia; Casas, Lidia (2007), “Objeción de conciencia y salud reproductiva en Chile: dos casos paradigmáticos”. Revista Acta bioética, 13 (2). Recuperado de http://www.scielo.cl/pdf/abioeth/v13n2/art07.pdf

Ídem (2006), “Aportes al debate sobre el aborto en Chile: derechos, género y bioética”, Revista Acta bioética, 12 (2). Recuperado de www.scielo.cl/ pdf/abioeth/v12n2/art11.pdf

Jakobs, Günther (1997), Derecho Penal. Parte General. Fundamentos y teoría de la imputación, (traducción Cuello Contreras - Serrano González de Murillo), segunda edición, Editorial Marcial Pons, Madrid.

Bustos Ramírez, Juan, Hormazábal Malaree, Hernán (2005), Nuevo sistema de Derecho Penal, Editorial Trotta, Madrid, España. 
Cadarso, P. (2014), Principales teorías sobre el conflicto social, Recuperado de http://www.google.cl/url?sa=t\&rct=j\&q=\&esrc=s\&source=web \&cd=1\&ved=0CCcQFjAA\&url=http\%3A\%2F\%2Fdialnet.unirioja.es\% 2Fdescarga\%2Farticulo\%2F241031.pdf\&ei=JHvhUpGVEcq0sQTgnYHIAQ\&usg= AFQjCNGKaVajhJPN2ruVQxTLgPDASvMhrQ\&bvm=bv.59930103,d.cWc

Casas L. (1996), Mujeres procesadas por aborto. Foro Abierto de Salud y Derechos Reproductivos, Santiago de Chile.

Eiser, Albin (1999), Nuevos horizontes en la Ciencia Penal. Una Justicia Penal a la Medida del ser Humano, Editorial Belgrano, Buenos Aires, Argentina.

Entelman, Remo (2002), Teoría de conflictos. Hacia un nuevo paradigma. Editorial Gedisa, Barcelona.

Ferrajoli, Luigi (1990), Derechos y Garantías. La ley del más débil, Introducción de P. Andrés Ibáñez, trad. cast. de P. Andrés Ibáñez y A. Greppi, Trotta, Madrid.

Foro de Salud y Derechos Sexuales y Reproductivos y Red de Salud de las Mujeres Latinoamericanas y del Caribe (2005), Atención Humanizada del Aborto Inseguro en Chile. Programa de Acción de la "Conferencia Internacional sobre Población y Desarrollo”, Santiago.

Galaway, Burt (1985), "Victim participation in the penal corrective process", en Revista Victimology, An International Journal, Vol. 10, Estados Unidos.

García-Pablos De Molina, Antonio (1988), Manual de Criminología. Introducción y teorías de la criminalidad, Editorial Espasa, Madrid.

García Pascual, Cristina (2007), “Cuestiones de vida y muerte. Los dilemas éticos del aborto”. Revista Derechos y Libertades, $\mathrm{N}^{\circ} 16$, época II, enero 2007, pp. 181-209. Recuperado de http://orff.uc3m.es/ bitstream/handle/10016/7135/DyL-2007-GarciaPascual.pdf?sequence=1

Garrido Montt, Mario (2010), Derecho Penal, parte especial, t. III, Editorial Jurídica de Chile, cuarta edición.

Gavrielides, Theo (2012), Waves of Healing. Using Restorative Justice with Street Group Violence. IARS publications, United Kingdom.

Henríquez Herrera, Ian (2000), “El derecho ante los desafíos de las biotecnologías: la cuestión sobre el inicio de la vida humana”. En Anuario de Filosofía Jurídica y Social. Edeval, Valparaíso, Chile. 
Langon Cunarro, Miguel (2000), “La teoría de la vergüenza reintegrativa de John Braithwaite”, en Revista de la Facultad de Derecho. Universidad de la República, $\mathrm{N}^{\mathrm{o}}$ 18, Montevideo.

Lask, B (1975), "Short-term Psychiatric Sequelae to Therapeutic Termination of Pregnancy”, Br J Psychiatry.

Marshall, Tony (1999), Restorative Justice, Editorial Overview, Nueva York.

Martínez, José Agustín (1940), Código de Defensa Social, Jesús Montero Editor, Cuba.

Maturana, Humberto (1991), El sentido de lo humano. Editorial JCSaez, Santiago.

Mera González-Ballesteros, Alejandra (2009), “Justicia Restaurativa y Proceso Penal Garantías Procesales: límites y posibilidades”, Revista Ius Et Praxis, vol. 15, N², año 2009, pp. 165-195, Santiago.

Ossandón Widow, María Magdalena (2012), “Aborto y Justificación” en Revista Chilena de Derecho, vol. 39, N², 2012, pp. 325-369, Santiago.

Rabinovich-Berkman, Ricardo (2014), Algunas reflexiones más sobre el aborto. Cátedra de Problemas éticos contemporáneos, Programa de Doctorado Intensivo en Derecho, Universidad de Buenos Aires, Argentina.

Ídem (2014), Frauennot-Frauenglûck. Sobre una poco conocida película de Eisenstein (¿el primer film “abortista” de la historia?). Universidad de Buenos Aires, Buenos Aires.

Rodríguez, Luis (2001), “La protección jurídica del nasciturus”. Las tesinas de Belgrano. Universidad de Belgrano, Departamento de investigación Facultad de Derecho y Ciencias Sociales, número 14. Recuperado de http:// www.ub.edu.ar/investigaciones/tesinas/14_valcarcel.pdf

Soto, Yvette; Román, Zinthya; Rojas, Raúl (2009), “Embarazo compartido, ¿Decisión compartida?: Hasta que punto puede el padre pedir que su mujer le notifique su decisión de someterse a un aborto". Revista Jurídica de LexJuris de Puerto Rico. Vol. 14, Nº1. Recuperado de http:// www.lexjuris.com/revista/opcion1/2009/Embarazo\%20Compartido.htm

Schmitz, J. (2011), ¿Qué son las prácticas restaurativas? Instituto Latinoamericano de prácticas restaurativas. Recuperado de http://ilapr.iirp.edu/ wp-content/uploads/2012/01/Que-son-las-PR.pdf , Lima

Villan Durán, Carlos (2012), Curso de Derecho Internacional de los Derechos Humanos, Trotta, Madrid. 
Polis, Revista Latinoamericana, Volumen 15, $N^{\circ}$ 43, 2016

Zaffaroni, R. (1998), En busca de las penas perdidas, Editorial Ediar S.A., Buenos Aires.

Recibido: 07.07.2014

Aceptado: 30.06.2015 